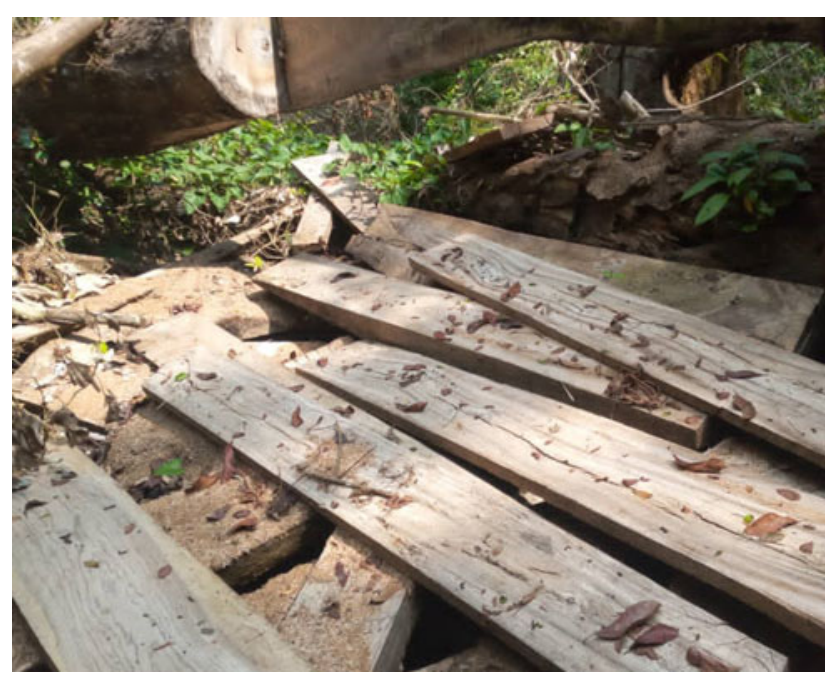

Wood of the Critically Endangered African zebrawood Microberlinia bisulcata logged illegally in Cameroon's Ebo forest.

wood is high because of its unique colour, texture and hardness. The species is not listed on the CITES appendices, although indiscriminate logging is a major problem, including a current increase in the Ebo forest, which was previously considered a safe haven for this and other species.

During August 2020-March 2021 we surveyed the Ebo forest to collect information on the rate of harvesting of this species and on the actors involved in the trade. We estimated that c. $2 \mathrm{t}$ of $M$. bisulcata are smuggled out of the forest every month. In February 2020 the area was gazetted as a logging concession. Given the current rate of illegal harvesting, we predict that within the next 2 years all seed-bearing individuals will have been logged, pushing the species to the brink of extinction. We identified five groups of actors involved in the trade of this wood: initiators (landowners, or locally influential people), prospectors (local men paid to find and mark trees), harvesters (local men paid to cut the marked trees), transporters (owners of trucks paid to transport the logged wood to the nearby city of Douala) and buyers (local businessmen or foreigners). We learnt that Chinese traders based in Douala pay USD $600 / \mathrm{m}^{3}$ of M. bisulcata wood, the price of which as doubled since 2018. The high price is probably the main reason for the current increase in illegal commercial harvesting. In addition, however, the decision to gazette the Ebo forest as a logging concession has inadvertently encouraged local people to log valuable timber products before they are forbidden to access the forest.

Based on our findings, we make the following recommendations: (1) the Ebo forest should be gazetted as a National Park, (2) the area needs to be reforested urgently with M. bisulcata, (3) alternative livelihood activities need to be implemented for the people living in the vicinity of the Ebo forest, and (4) M. bisulcata needs to be listed on a CITES appendix, prohibiting international trade in its wood.
ERIC DJOMO NANA (๑ orcid.org/0000-0002-6118-9359),

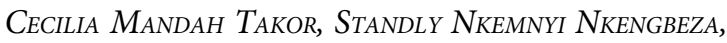

BARTHELEMY TCHIENGUE, ERIC T. NGANSOP and

EMMANUEL TCHOPWE National Herbarium of Cameroon,

Yaoundé, Cameroon. E-mail eric.nana@natconbio.org

This is an Open Access article, distributed under the terms of the Creative Commons Attribution licence CC BY 4.0.

\section{Gender and illegal wildlife trade: overlooked and underestimated}

Despite increasing awareness globally of the need to integrate and mainstream a gendered approach in international policy arenas, there remains gender-blindness in understanding and responding to illegal wildlife trade. Research, thinking and responses to illegal wildlife trade have generally failed to look at half of the world's population, and gender issues more generally, hence missing important entry points to understand, prevent and tackle the issue. Illegal wildlife trade involves and affects men and women differently, and gender norms play an important part in influencing behaviours and attitudes along the illegal wildlife trade value chain. Put simply, failing to consider gender is like tackling wildlife crime with one hand tied behind your back. The place, role and dynamics of women and men in relation to this trade differ, so it is crucial to consider the gendered implications of illegal wildlife trade if we are to respond in an inclusive and efficient manner to improve the likelihood of conservation success.

In July 2021, WWF released a report, Gender \& Illegal Wildlife Trade: Overlooked and Underestimated, which paves the way for more inclusive and informed responses. The report gives an overview of available gender-informed research, field evidence and concepts relating to poaching, trafficking and consumption of wildlife products, and international governance and policy. It identifies key gaps and research needs, explains why looking at illegal wildlife trade through the lens of gender is important, and provides recommendations and a practical framework to help conservation practitioners bring gender analysis into programmes, policies and interventions at local, national and global scales. This gender framework will be available online in September 2021.

Another WWF report, also released in July 2021, Towards Gender Equality in the Ranger Workforce highlights how greater gender equality in the ranger workforce could reduce ranger misconduct and improve conservation outcomes, relationships with communities, and park and wildlife management.

We hope these reports and the gender framework will provide a basis from which to deepen understanding around the importance of integrating gender into conservation. Research and publication were funded by the Swedish International Development Cooperation Agency. For more information, contact Rob Parry-Jones, Head, Wildlife Crime Initiative 
(rparryjones@wwfint.org) or Tamara Léger, Illegal Wildlife Trade Global Policy Coordinator (tleger@wwfint.org).

JONI SEAGER Bentley University, Waltham, USA

E-mail jseager@bentley.edu

RoB PARRY-JONES and TAMARA LÉGER WWF International, Gland, Switzerland

This is an Open Access article, distributed under the terms of the Creative Commons Attribution licence CC BY 4.0.

\section{New reforestation project in southern Madagascar to prevent the extinction of local endemic species}

Madagascar harbours numerous endemic plant and animal species and is one of the most important biodiversity hotspots in this respect. Although conservation organizations have tended to focus on the better known national parks of Madagascar, there are forest fragments that still hold locally endemic biodiversity. One of these is a group of forest fragments within the south-east Lavasoa-Ambatotsirongorongo mountains. This area is a predominantly humid, transitional forest as a result of the position of these mountains on the steep ecological gradient between the dry spiny forest to the west and the humid forest to the north. Because of the gradient, this area is one of only a few known locations in the country where species from both dry and humid forests are sympatric. Although some of the lemur species present also occur elsewhere, the Critically Endangered Bemanasy mouse lemur Microcebus manitatra is only known from this area, and the Endangered Lavasoa dwarf lemur Cheirogaleus lavasoensis is known only from this site and KalambatritraSahalava, $170 \mathrm{~km}$ to the north. The latter species was included in the list of the World's 25 Most Endangered Primates in 2014-2016, and the former was included in the most recently published list (2018-2020), making Ambatotsirongorongo one of the top priorities for lemur conservation. The remaining forest also holds one of the last populations of the Critically Endangered gecko Phelsuma antanosy.

We are pleased to announce the launch of a new reforestation programme to respond to the urgent restoration and conservation needs in this area. The project will be led by a consortium that include a Malagasy enterprise (Tropical Biodiversity and Social Enterprise) with 2 decades of experience in restoring the local flora, and two academic institutions, Oxford Brookes University and Hamburg University, which play a major role in studying lemurs and the endemic biodiversity of Madagascar. The project, launched in July 2021, includes a plan to plant 4 million native trees over the next 4 years to restore the endemic species within the protected area of Ambatotsirongorongo. This will include the establishment of 300 ha of fast-growing trees as firebreaks, to demonstrate dynamic agroforestry to villagers living outside the protected area and thus to relieve pressure on the remaining native forest. An additional aim is to revitalize community management of the protected area. Ecosia, a Berlin-based not-for-profit search engine that channels $80 \%$ of its revenue to finance tree planting projects, has agreed to fund this ambitious plan, and the non-profit association Naturefund will support the agroforestry component. Field studies on the biota and of the socio-economic situation and its development over time will accompany the reforestation programme.

GiUSEPPE Donati (৫ orcid.org/0000-0002-4803-0642) School of Social Sciences, Oxford Brookes University, Oxford, UK E-mailgdonati@brookes.ac.uk

JeAN-BAPTISTE Ramanamanjato Tropical Biodiversity \& Social Enterprise, Fort-Dauphin, Madagascar

LLOYD J. BLUM Department of Agricultural Economics and Rural Development, Georg-August-University, Göttingen, Germany

EDGAR FLURY Environmental Technology and Management, University of Applied Science, Switzerland

JOERG U. GANZHORN Animal Ecology and Conservation, Universität Hamburg, Germany

This is an Open Access article, distributed under the terms of the Creative Commons Attribution licence CC BY 4.0.

\section{Mysterious death of 18 wild elephants in Nagaon District, Assam, India}

On 13 May 2021, a number of wild Asiatic elephants Elephas maximus in Bamuni Reserve Forest, Nagaon District, Assam, India, were reported dead. Large herds of elephants frequently traverse one of two corridors originating from Kaziranga National Park: (1) south-westwards to Doboka, via Swang Reserve Forest, and (2) southwards to North Karbi Anglong Wildlife Sanctuary. Local people discovered the dead elephants in the Bamuni Hills and, as we were nearby working in these corridors, we visited the location, where we observed 18 dead elephants on a hilltop: five males, and $13 \mathrm{fe}$ males, of which four were juveniles. The area had received incessant rain for several days preceding the incident, along with heavy thunderstorms and lightning. Local people suggested lightning as the possible cause of the deaths. On 14 May, forest officials of the Assam government visited to gather evidence, assisted by veterinary officials who conducted post-mortems. Preliminary reports, based on evidence of burns on the trunks and fur of two of the elephants, along with a few burnt teak trees, support the hypothesis that the deaths were a result of lightning. 